\title{
Smart Gas Booking System
}

\author{
${ }^{1}$ Manisha S.M, ${ }^{2}$ Shanmugapriya. A \\ ${ }^{1}$ Department of CSE, ${ }^{2}$ Assistant Professor/Dept. CSE, Sri Ramakrishna Engineering College, \\ Coimbatore, India. ${ }^{1}$ manisha.1601118@srec.ac.in, ${ }^{2}$ shanmugapriya@srec.ac.in
}

\begin{abstract}
Without LPG, cooking would be difficult, as it makes cooking easy, fast and economical. Thus LPG became crucial for cooking because of its desirable characteristics. Though there are various methods available for booking gas such as online booking, telephonic booking, etc, it is difficult for the users to remember the due date and book the gas as per the schedule. Many times people forget to book gas and suffer gas shortage. Smart Gas Booking System was proposed to avoid such situation. The aim of the project is to present a system that automatically books a LPG cylinder when the gas is close to empty by sending a notification to the user. An alert message is send to the user when the gas is about to empty. The user decides whether to book the gas or not. Based on his request the gas would be booked. And reply notification will be sent to the user about the booking status.
\end{abstract}

Keywords - Arduino, GSM Module, IOT, Load Cell, LPG, SIM800l

\section{INTRODUCTION}

LPG is a clean-burning, efficient, portable and low carbon fossil fuel. It has high calorific value and creates extremely low levels of carbon dioxide. It is much safer than other sources of fuel and its harmful rate is comparatively low. LPG is colourless and odourless gas. Odour is added for safety purposes. LPG is used in various sectors such as industrial, agricultural, residential, commercial, and automobiles. LPG is mainly used in cooking, as vehicular fuel and producing electrical energy by running turbines. In the day to day life, we all are busy with our schedules and it is difficult for us to know the level of LPG gas in the cylinder and book the gas before it gets empty. If LPG gets emptied without prior gas booking, we suffer gas shortage and cooking would be difficult. So it is important to monitor the LPG level and book the gas before it gets emptied.

The Smart Gas Booking system helps us to avoid such kind of problem in our daily life. The system consists of a load sensor that monitors LPG emptiness all the time. If LPG is very close to finish then the system alerts us by sending SMS and sends message to the Gas Agency for ordering the LPG cylinder. The system continuously monitors the level of the LPG present in the cylinder using load cell, if the gas level reaches below the threshold limit the old empty cylinder is replaced by new one in time by booking cylinder using a GSM module.

The aim of the project is to continuously measure the gas level in the cylinder and to alert the user when the weight of the cylinder goes below the fixed point. The load cell in the system continuously measures the weight of the cylinder and sends high or low signals to the arduino. If the arduino receives low signals from the load cell, it sends signals to the GSM Module. The GSM Module in turn sends alert message to the customer. And the gas will be booked according to the customer approval.

\section{Literature SURVEY}

In this paper [1] gas level is detected with the help of load sensor. User is alerted via SMS using GSM Module. In this paper [2] gas level is detected using load cell and alerts the user via buzzer and also sends SMS. In this paper [3] MQ2 gas sensor and load cell are used to detect gas leakage and gas shortage respectively. In this paper [4] MQ6 gas sensor is used to detect gas leakage and the user is alerted via SMS services. In this paper [6] load cell is used for gas level monitoring and the user is notified with message services. In this paper [8] gas level is monitored using load cell and MQ6 sensor. Customer is alerted via buzzer and message service.

\section{Proposed System}

In the proposed system, the gas container is placed above the load cell. The load cell continuously monitors the amount of gas in the cylinder and sends signals to the arduino. Arduino UNO is the microcontroller used in the system. All the input output devices such as Load Cell, GSM Module and LCD Display are interfaced with Arduino UNO. The LCD Display displays the amount of gas in the cylinder. The load cell continuously sends high or low signals to the arduino. The HX711 Load Cell amplifier amplifies the load cell signals and then sends it to the arduino UNO. When the arduino receives low pulse from the load cell, it sends signals to the GSM Module to alert the user. A SIM inserted in the GSM Module sends SMS to the registered mobile number. AT commands are used for 
this purpose. User will receive message stating that gas in the cylinder is about to get completed. The user in turn replies approval or rejection message. After receiving the user's approval message gas will be booked.

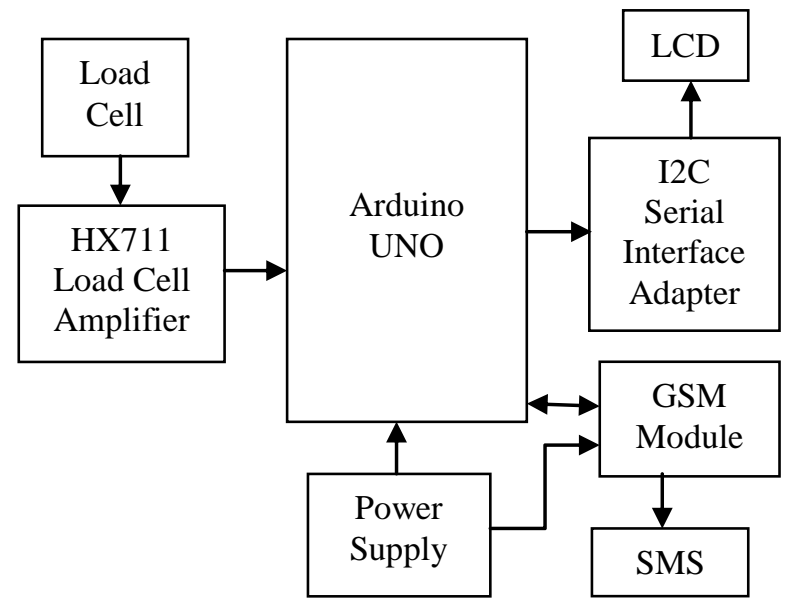

works on magneto static effect or piezoelectric effect.

\section{HX711 Load Cell Amplifier}

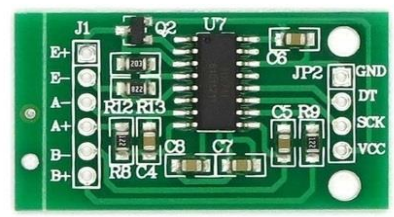

Figure 4. HX711 Load Cell Amplifier

HX711 is a 24-bit analog-to-digital converter (ADC). It was specially designed for amplification purpose. The signals read by the Load Cell need to be amplified so that they could be read by an Arduino. HX711 is used for this amplification purpose.

\section{GSM Module}

Figure 1. Block Diagram of the system

\section{COMPONENTS DESCRIPTION}

\section{A. Arduino UNO}

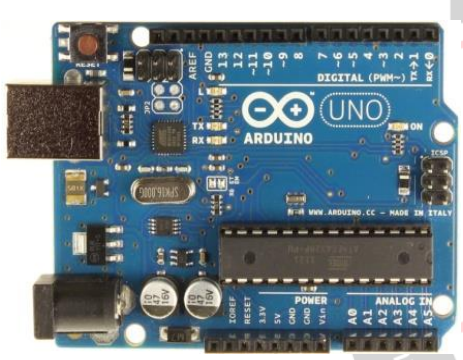

Figure 2. Arduino UNO

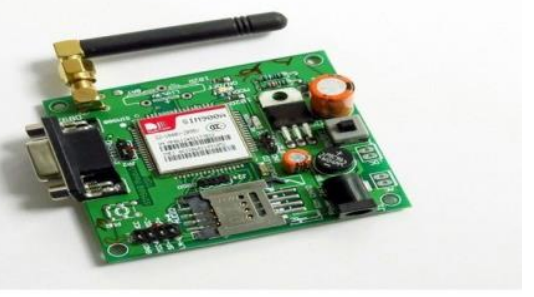

Figure 5. GSM Module

A GSM module is employed to determine communication between a mobile device and a computer. The module consists of a GSM module along with SIM8001. It is used to alert the user with message services.

\section{E. $L C D$}

The Arduino-Uno is a micro controller board based on the ATmega328P microcontroller. It is an open-source platform. It is built with 14 digital input/output pins, 6 analog inputs, a $16 \mathrm{MHz}$ crystal oscillator, a USB connection, a power jack, an ICSP header, and a reset button.

\section{B. Load Cell}

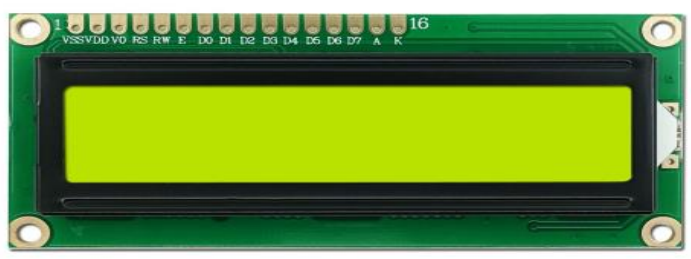

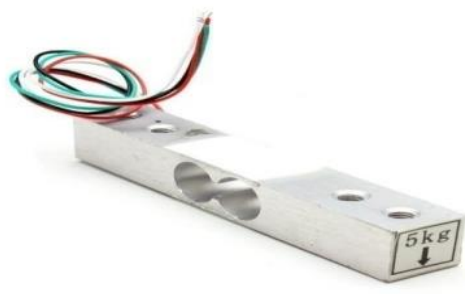

Figure 3. Load Cell
Figure 6. LCD

A liquid-crystal display (LCD) is a flat-panel display. Liquid crystal display consists of several layers which include two polarized panel filters and electrodes. LCD contains two interfaces on upper and lower side of the module. Its operating power supply ranges from $+5.0 \mathrm{~V}$ or $+3.0 \mathrm{~V}$.

Load cell is a transducer. It generally consists of a spring element on which strain gauges have been placed. This spring element is made of steel or aluminium. Here, Load cell is used to measure the weight of the cylinder. Load cell 


\section{F. I2C Serial Interface Adapter}

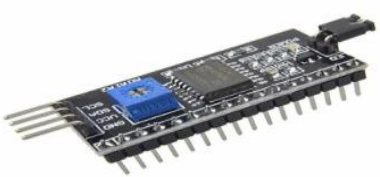

Figure 7. I2C Serial Interface Adapter

I2C Serial Interface Adapter Module is employed for $16 \times 2$ LCD Display. This module helps in the transfer of data between Arduino and LCD. It uses the PCF8574T IC chip. This module simplifies connecting an Arduino to a $16 \times 2 \mathrm{LCD}$. Its operating power supply is $5 \mathrm{~V}$.

\section{G. Power Supply}

Power supply is employed to provide electric power to the connected devices. It converts current from the source to the right voltage, current, and frequency. It is used to regulate power, to convert power to direct current and to vary voltage.

\section{EXPERIMENTAL RESULT}

The experimental setup is shown within the figure 8 . When the gas within the cylinder is close to empty the load cell within the system sends low pulses to the arduino. The Arduino sends signals to the GSM Module to alert the user. The GSM sends alert message to the registered mobile number notifying that the LPG is close to finish. When the system receives approval message from the customer, it books the cylinder and notifies the customer with "Gas Booking Successfully" message.

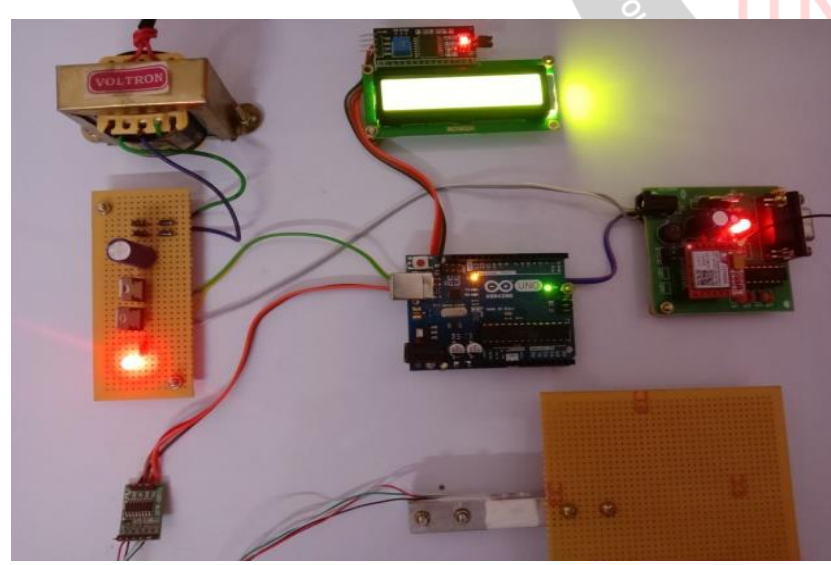

Figure 8. Experimental setup

\section{CONClusion}

The problems faced due to improper gas booking could be avoided by Smart Gas Booking System. Since LPG became crucial for day-to-day life, it is very important to track the LPG level and book the gas as per the schedule. When the LPG is about to finish, the system alerts the user with SMS and based on the user approval the gas is booked.
It also sends notification to the user based on the booking status. Thus the system makes gas booking easier.

\section{FutURe SCOPE}

Voice based feedback system can be included. User will get intimation through pre-recorded voice messages along with the SMS service. Power Supply could be replaced with battery.

\section{REFERENCES}

[1] Sony Shrestha, V. P. Krishna Anne and R.Chaitanya "IOT Based Gas Management System"- Third International Conference on Trends in Electronics and Informatics (ICOEI)2019.

[2] Mr.Sameer Jagtap, Prajkta Bhosale, Priyanka Zanzane, Jyoti Ghogare "LPG Gas Weight and Leakage Detection System Using GSM"- International Journal for Research in Applied Science \& Engineering Technology (IJRASET)March 2016.

[3] Gokula kaveeya S, Gomathi S Kavipriya K, Kalai selvi A, Sivakumar S "Automated Unified System for LPG using Load Sensor"- International Conference on Power and Embedded Drive Control (ICPEDC) 2017.

[4] Kumar Keshamoni, Sabbani Hemanth "Smart Gas Level Monitoring, Booking \& Gas Leakage Detector over IoT"- 7th International Advance Computing Conference 2017.

[5] Alan Macker, Anil Kumar Shukla , Sagarika Dey, Jyoti Agarwal "ARDUINO Based LPG gas Monitoring \& Automatic Cylinder booking with Alert System" 2nd International Conference on Trends in Electronics and Informatics (ICOEI) 2018.

[6] Prof. Gautami G. Shingan, S.V. Sambhare, V. S. Bhokare, A. L. Nikam, H. D. Shinde "Smart Gas Cylinder:Leakage Alert and Automatic Booking"- International Conference on Energy, Communication, Data Analytics and Soft Computing (ICECDS) 2017.

[7] Digambar Surse, Swati Talekar, Tejal Suryawanshi, Prof. M. R. Gaikar "Smart Gas Leakage Detection"- International Journal of Innovative Research in Computer and Communication Engineering 2016

[8] G.Rathanasabhapathy, B. Durga Devi, N. Gopi Krishnan, S. Gowsalya, M.Jagadeesan "Automatic gas booking and leakage detection using embedded system with safety guards"- International Journal of Intellectual Advancements and Research in Engineering Computations 2018

[9] Tamizharasan. V, Ravichandran.T, Sowndariya.M, Sandeep.R, Saravanavel.K "Gas Level Detection and Booking System"- 5th International Conference on Advanced Computing \& Communication Systems (ICACCS) 2019

[10] Rosemin Thanga Joy, D. Joshphin Janita, K. Anitha, A. Hotlin. "SMART GAS LEVEL MONITORINGAND BOOKING SYSTEM"- International Journal of Emerging Technology in Computer Science \& Electronics (IJETCSE) April 2018 